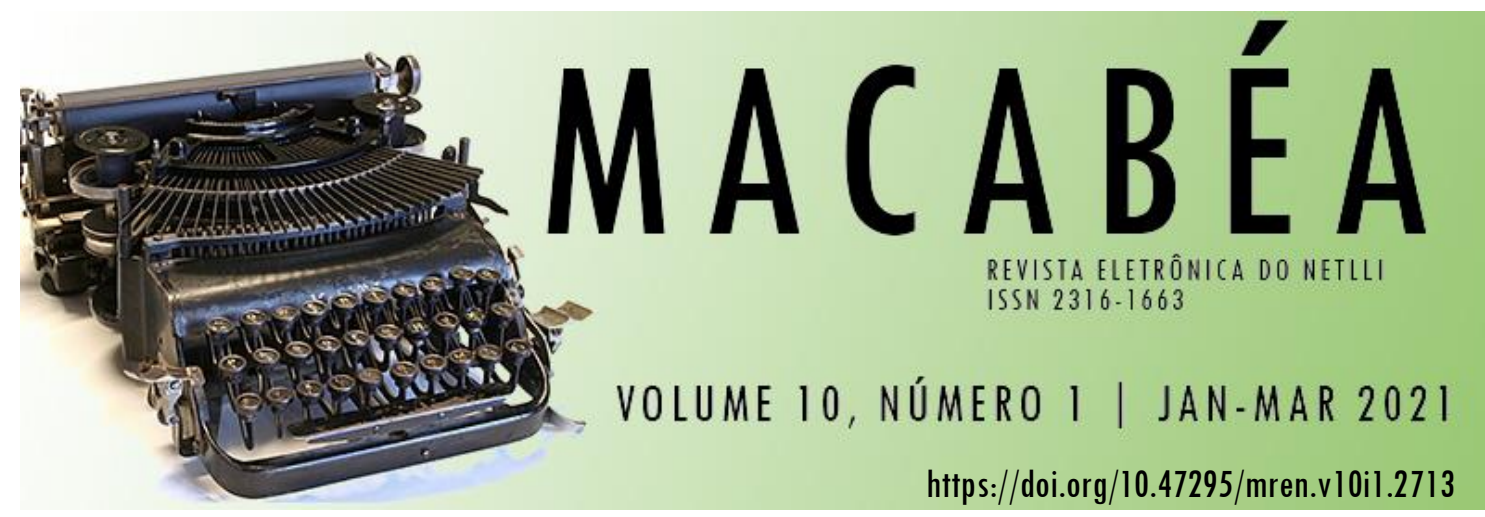

\title{
PRÁTICAS DE LEITURA EM PROJETOS DE LETRAMENTO: REFLEXÕES TEÓRICO-METODOLÓGICAS
}

\section{READING PRACTICES IN LITERACY PROJECTS: THEORETICAL- METHODOLOGICAL REFLECTIONS}

ANDRESSA REGIANE GESSER

\author{
RESUMO | INDEXAÇ̃̃O | TEXTO | REFERÊNCIAS | CITAR ESTE ARTIGO | A AUTORA \\ RECEBIDO EM 28/07/2020 • APROVADO EM 03/09/2020
}

\begin{abstract}
Starting from the perspective of New Literacy Studies, this article aims to: theoretically discuss the main concepts belonging to this field of research; discuss reading practices in literacy projects; and analyze some methodological proposals on reading practices in literacy projects, presented in the literature. The perspective of New Literacy Studies was based on Barton e Hamilton (1998), Gee (1994); Hamilton, (2000); Kleiman (1995, 2000), Oliveira (2010) e Street (2000), and that of the discursive genres in Bakhtin (2011). This work is located in the field of Applied Linguistics and follows a qualitative and interpretative methodology. This work discussed the concepts of literacy as a social practice, literacy events and practices, literacy models in teaching, literacy projects, and language, discourse genres and reading practices in literacy projects. As results, it was identified that literacy projects have a fundamental role in making reading practices more reflective, critical and transformative, when they incorporate meanings from social practices. We conclude that it is essential to incorporate social practice and the collective interest of students in the selection of discursive genres that will be addressed in reading practices.
\end{abstract}




\section{Resumo}

Partindo-se da perspectiva dos Novos Estudos do Letramento (New Literacy Studies), este artigo objetiva: discutir teoricamente os principais conceitos pertencentes a esse campo de pesquisa; discutir as práticas de leitura em projetos de letramento; e analisar algumas propostas metodológicas sobre as práticas de leitura em projetos de letramento presentes na literatura. A perspectiva dos Novos Estudos do Letramento foi embasada em Barton e Hamilton (1998), Gee (1994); Hamilton, (2000); Kleiman (1995, 2000), Oliveira (2010) e Street (2000), e a dos gêneros discursivos em Bakhtin (2011). Este trabalho se situa no campo da Linguística Aplicada e segue uma metodologia qualitativa e interpretativista. Foram discutidos os conceitos de letramento como prática social, eventos e práticas de letramento, modelos de letramento no ensino, projetos de letramento e a linguagem, gêneros do discurso e práticas de leitura em projetos de letramento. Como resultados, identificou-se que os projetos de letramento, quando incorporam significados advindos das práticas sociais, têm um papel fundamental de tornar as práticas de leitura mais reflexivas, críticas e transformadoras. Conclui-se que é fundamental incorporar a prática social e o interesse coletivo dos estudantes na seleção dos gêneros discursivos que serão abordados nas práticas de leitura.

\section{Entradas para indexação}

KEYWORDS: Reading practices. Literacy Projects. Discursive genres.

PALAVRAS-CHAVE: Práticas de Leitura. Projetos de Letramento. Gêneros discursivos.

\section{Texto integral}

\section{INTRODUÇÃO}

A reflexão acerca das práticas de leitura e escrita no ensino de língua portuguesa é muito importante, pois é por meio da língua que os discursos se manifestam socialmente. Além disso, o modo como essas práticas são organizadas pode tanto contribuir para a promoção da participação social dos estudantes, como para obstaculizar esse processo. Ademais, o modo como essas práticas são organizadas pode corroborar a construção de processos educativos voltados ao desenvolvimento de indivíduos críticos e reflexivos, capazes de questionar a realidade e de buscar transformações na sociedade, sejam de ordem política ou social (FREIRE, 1996, 2003; GIROUX, 1990).

0 ensino de língua portuguesa, em muitos contextos educacionais, foi predominantemente pautado em uma visão tradicional de escola, com uma perspectiva conteudista. Os conteúdos ensinados, muitas vezes, naturalizavam os processos de dominação e partiam de uma visão de língua que excluía estudantes com características econômicas e culturais diversas, engendradas a partir da intersecção entre gênero, raça, classe social e outros marcadores sociais da diferença (VENCATO, 2014). Além disso, geralmente esses conteúdos eram ensinados sem nenhuma relação histórico-cultural com o meio em que os 
estudantes estavam inseridos e não tratavam o ensino de modo crítico e reflexivo. Essa visão de educação bancária que não considera os conhecimentos prévios dos estudantes, nem o seu contexto histórico-político e social, foi criticada por Paulo Freire $(1996,2003)$ por não promover o desenvolvimento de cidadãos críticos. 0 autor defende uma educação crítica, que privilegie um olhar para os contextos sociais buscando a compreensão da realidade e a transformação social.

Visando o rompimento da perspectiva tecnicista e a promoção de um ensino que objetive a criticidade e a reflexão dos estudantes e também de todos os envolvidos no contexto escolar, muitos autores vêm propondo projetos de letramento baseados na perspectiva dos Novos Estudos do Letramento para o ensino das práticas de leitura e de escrita (BRANDÃO; TINOCO, 2017; KLEIMAN, 2000, 2007, 2009, 2012; OLIVEIRA, 2010; OLIVEIRA; TINOCO; SANTOS, 2014; ROJO, 2009; SANTOS MARQUES; KLEIMAN, 2019).

Esses autores consideram que o ensino das práticas de leitura e escrita por meio de projetos de letramento pode promover a aprendizagem significativa, no sentido de ser crítica, reflexiva, coletiva e coerente com o contexto sócio-histórico dos estudantes. Segundo Kleiman (2000, p. 238), o projeto de letramento é

\begin{abstract}
um conjunto de atividades que se origina de um interesse real na vida dos alunos e cuja realização envolve o uso da escrita, isto é, a leitura de textos que, de fato, circulam na sociedade e a produção de textos que serão lidos, em um trabalho coletivo de alunos e professor, cada um segundo sua capacidade. 0 projeto de letramento é uma prática social em que a escrita é utilizada para atingir algum outro fim, que vai além da mera aprendizagem da escrita (a aprendizagem dos aspectos formais apenas), transformando objetivos circulares como "escrever para aprender a escrever" e "ler para aprender a ler" em ler e escrever para compreender e aprender aquilo que for relevante para 0 desenvolvimento e a realização do projeto.
\end{abstract}

Destaca-se, a partir da perspectiva de Kleiman (2000), que os projetos de letramento devem ser planejados considerando os interesses dos estudantes e envolver práticas de leitura e de escrita de textos histórica e socialmente situados. Assim, corroborando o pensamento de autores como Freire (1996), deve-se ir além da perspectiva utilitarista de aprendizagem da leitura e escrita, instrumentalizando os estudantes para o desenvolvimento de uma leitura crítica da realidade social.

Em relação ao ensino da leitura, Paulo Freire afirma que "a leitura do mundo precede a leitura da palavra" (FREIRE, 2003, p. 9), ou seja, para o autor, a leitura sempre envolve um olhar crítico para a realidade social. Assim, os sujeitos podem questionar os modelos sociais, políticos e ideológicos vigentes na sociedade, promovendo sua emancipação e o empoderamento por meio da linguagem e do pensamento crítico.

Diante da contextualização apresentada, este trabalho busca discutir teoricamente os principais conceitos pertencentes aos Novos Estudos do Letramento. Também se propõe a discutir as práticas de leitura em projetos de 
letramento e analisar propostas metodológicas para práticas de leitura em projetos de letramento presentes na literatura.

0 trabalho está situado no âmbito da Linguística Aplicada e segue uma metodologia qualitativa e interpretativista. Além disso, as reflexões apresentadas partem da perspectiva dos Novos Estudos do Letramento, que entendem as práticas de leitura e escrita como prática social e da pedagogia crítica, visando "[...] compreender e criticar o contexto histórico e sociopolítico da escolarização, bem como desenvolver as práticas pedagógicas que buscam não só mudar a natureza da escolarização, mas também da sociedade mais ampla." (PENNYCOOK, 1998, p. 42).

Este trabalho está dividido em três seções. A introdução contextualizou o estudo. Na segunda seção, serão apresentadas as reflexões teóricas acerca dos novos estudos do letramento, abordando conceitos como evento e prática de letramento, modelos de letramento, os projetos de letramento, e a linguagem, os gêneros discursivos e a leitura nos projetos de letramentos. Na terceira seção, serão analisadas duas propostas metodológicas que envolvem a leitura em projetos de letramento. Por fim, serão apresentadas as considerações finais do trabalho.

\section{REFLEXÕES E CONTRIBUIÇÕES TEÓRICAS}

Nesta seção, será contextualizado o campo dos Novos Estudos do Letramento (New Literacy Studies). Para tanto, primeiramente serão brevemente cotejadas as perspectivas de letramento tradicional e de letramento como prática social. Em seguida, serão apresentados os conceitos de eventos e práticas de letramento. Posteriormente, serão destacadas as contribuições do uso desses construtos teóricos na prática, por meio de projetos de letramento. Por fim, será abordada uma discussão acerca do papel da linguagem, dos gêneros do discurso e da leitura em projetos de letramentos.

\subsection{LETRAMENTO: DA PERSPECTIVA TRADICIONAL À PERSPECTIVA SOCIAL}

Inicialmente, o termo letramento era caracterizado como a habilidade de ler e escrever de modo estrito. Essa perspectiva foi criticada por Gee (1994), pelo fato de não levar em consideração o contexto sociocultural e as relações humanas: "a visão tradicional do letramento como a capacidade de ler e escrever tira o letramento de seus contextos socioculturais e o trata como uma habilidade cognitiva não social, com pouco ou nada a ver com as relações humanas." (GEE, 1994, p. 67 tradução nossa).

Essa visão tradicional de letramento, segundo o autor, é a base da divisão entre culturas orais e escritas, divisão que pode até mesmo ser um instrumento de opressão. No nível cultural, o letramento, nessa visão tradicional, pertence à cultura complexa, moderna e sofisticada e, no nível individual, pode levar a ordens maiores de inteligência. Nessa direção, Gee (1994) afirma que há um grande número de estudos, denominados Novos Estudos do Letramento, que substituem a visão 
tradicional de letramento por uma abordagem sociocultural. Esses autores pretendem adicionar os aspectos socioculturais ao letramento, levando em consideração o letramento não como algo singular, mas como um conjunto plural de práticas sociais. Diante dessa visão de práticas sociais na pluralidade, o termo letramento tornou-se 'letramentos' no plural.

Kleiman (2009) também diferencia a visão tradicional do letramento e a visão social, afirmando que "os Estudos do Letramento destacam, em contraposição às atividades fundamentadas na perspectiva não social da escrita, atividades vinculadas a práticas em que a leitura e a escrita são ferramentas para agir socialmente." (KLEIMAN, 2009, p. 4). Portanto, os estudos do letramento surgiram para dar conta da infinidade de práticas sociais que envolvem a leitura e a escrita de modo crítico.

Outra dicotomia que foi bastante discutida no campo é a dos modelos de letramento autônomo e ideológico (STREET, 1984). 0 modelo autônomo, tido como 'neutro' e sem ideologia, "pressupõe que há apenas uma maneira de o letramento ser desenvolvido, sendo que essa forma está associada quase que causalmente com o progresso, a civilização, a mobilidade social" (KLEIMAN, 1995 p. 21), ou seja, sem levar em consideração a realidade social. 0 modelo ideológico, por outro lado, defende que "as práticas de letramentos, no plural, são social e culturalmente determinadas, e, como tal, os significados específicos que a escrita assume para um grupo social dependem dos contextos e instituições em que ela foi adquirida." (KLEIMAN, 1995 p. 21).

Street (2003) critica essa dicotomia, destacando que essa nomenclatura do modelo de letramento autônomo é somente uma estratégia ideológica com o objetivo de disfarçar o modo como a abordagem supostamente neutra privilegia as práticas de letramento de grupos específicos de pessoas, isto é, dos grupos dominantes. Sendo assim, mesmo esse modelo sendo considerado neutro, apresenta em si uma ideologia bem marcada, pois "ensinar exige reconhecer que a educação é ideológica" (FREIRE, 1996, p. 125).

Diante disso, destaca-se, segundo Oliveira (2010), que os letramentos são (i) múltiplos, visto que englobam uma pluralidade de contextos sociais e culturais de uso da língua; (ii) dêiticos, pois evoluem e se transformam de acordo com o contexto sócio-histórico; (iii) ideológicos, já que cada grupo social busca assegurar seus interesses, crenças, valores, isto é, sua ideologia; (iv) culturais, porque as práticas de letramento englobam contextos culturais diferentes, e, por fim, (v) críticos, visto que é por meio deles que o indivíduo pode analisar, desafiar e transformar as forças opressoras da sociedade (OLIVEIRA, 2010).

\subsection{CONCEITOS RELACIONADOS AOS ESTUDOS DOS LETRAMENTOS}

Nas últimas décadas, muitos autores (BARTON; HAMILTON, 1998; HAMILTON, 2000; HEATH, 1982; STREET, 2000, entre outros) adentraram no campo dos Estudos do Letramento com o intuito de compreender os eventos e as práticas de leitura e escrita. Para Barton e Hamilton (1998), por exemplo, o letramento é um conjunto de práticas sociais, mediadas por eventos constituídos de 
textos escritos, em diferentes situações da vida, de modo situado historicamente. De acordo com os autores, as práticas de letramento são modeladas pelas instituições sociais e pelas relações de poder, fazendo com que alguns letramentos sejam considerados mais dominantes ou influentes do que outros.

Barton e Hamilton (1998) afirmam que é nas práticas sociais que o letramento cumpre seu papel por meio de eventos e práticas de letramento. Os eventos de letramento, segundo Heath (1982, p. 50 - tradução nossa), podem ser compreendidos como "[...] ocasiões em que a linguagem escrita é parte integrante da natureza das interações dos participantes e seus processos e estratégias interpretativas". Para Barton e Hamilton (1998), os eventos de letramento são atividades em que a escrita desempenha um papel, são episódios observáveis e contextualizados que emergem nas práticas sociais.

Apesar de Street (2000) afirmar que o conceito de evento de letramento é útil, pelo fato de se tratar de uma situação particular de interação com a linguagem que pode ser observada por pesquisadores, não há evidência, segundo o autor, de como os conceitos e as reflexões sobre a linguagem são construídos dentro de um evento de letramento. Diante disso, o autor sugere o conceito de práticas de letramento. As práticas de letramento, segundo Street (2000), lidam com os padrões de atividade que subjazem à participação em eventos, de modo a relacioná-los com formas particulares de se pensar e de se fazer a leitura e a escrita dentro de um contexto de modo mais amplo, cultural e social (STREET, 2000).

Para comparar os eventos e as práticas de letramento, Hamilton (2000) utiliza a metáfora do iceberg. De acordo com a autora, os eventos de letramento representam a ponta do iceberg, pois são episódios visíveis. Já as práticas de letramento são a parte que fica abaixo do topo do iceberg, sua base, visto que envolvem recursos como conhecimentos e sentimentos, propósitos e valores sociais que são invisíveis. As práticas de letramento, segundo a autora, podem ser somente inferidas a partir de evidências observáveis no contexto.

0 processo de letramento de indivíduos envolve a participação em eventos e em práticas de letramento. Sendo assim, Kalman (2003) afirma que, para um sujeito ser letrado, ele deve utilizar a língua escrita para participar do mundo social. Para isso, a autora (KALMAN, 2003, p. 39 - tradução nossa) destaca a importância da disponibilidade de recursos, isto é, "a presença física de materiais impressos, a infraestrutura para distribuição (biblioteca, pontos de venda de livros, revistas, jornais, serviços de correio, etc.)" e do acesso a esses materiais, ou seja, "oportunidades tanto para participar em eventos de língua escrita (situações em que o sujeito fica na frente de outros leitores e escritores) como para aprender a ler e escrever." (KALMAN, 2003, p. 39 - tradução nossa).

Apesar de os letramentos estarem presentes no cotidiano social dos indivíduos por meio dos eventos de letramento, muitos sujeitos não têm a disponibilidade e o acesso a tais eventos, devido à questão da desigualdade social apontada por Rojo (2009). Diante disso, ressalta-se a importância da escola no processo de letramento desses indivíduos a fim de engajá-los em práticas de leitura e escrita para agirem socialmente de modo crítico e reflexivo.

\subsection{PROJETOS DE LETRAMENTO}

Macabéa - Revista Eletrônica do Netlli | V.10., N.1., JAN.-MAR. 2021, p. 67-82 
Um modo de promover um ensino que vise a criticidade e a reflexão dos estudantes e também de todos os envolvidos no contexto escolar são os projetos de letramento. 0 ensino por meio de projetos pode tornar os sujeitos envolvidos protagonistas no desenvolvimento de práticas de leitura e escrita, bem como no desenvolvimento do olhar crítico para a sociedade. Em relação ao ensino por meio de projetos, as autoras Oliveira, Tinoco e Santos afirmam que

[...] o desenvolvimento de projetos na escola pode ser uma alternativa de ressignificação do fazer docente e discente desde que seja pressuposto um trabalho coletivo de planejamento e execução de atividades que têm objetivos e metas compartilhadas por profissionais com diferentes formações, que oferecem a sua contribuição para, juntos e com a participação ativa dos alunos, chegarem a um ponto definido prévia e coletivamente. (OLIVEIRA; TINOCO; SANTOS, 2014, p. 20)

Percebe-se que o trabalho educativo conduzido por meio de projetos de letramento pode promover a aprendizagem significativa, no sentido de ser crítica, reflexiva, coletiva e coerente com o contexto educacional. Os projetos de letramento, conforme explicado na introdução, são "uma prática social em que a escrita é utilizada para atingir algum outro fim, que vai além da mera aprendizagem da escrita" (KLEIMAN, 2000, p. 238), ou seja, os textos cumprem seu papel social.

Baltar (2010) também escreve sobre as práticas de letramento presentes nos projetos, destacando que os projetos de letramento consideram tanto as práticas de letramento dominantes quanto as práticas locais:

Os projetos de letramento, ao mesmo tempo em que devem levar em consideração diferentes mundos de letramento, as práticas de prestígio e as práticas locais de uso da escrita, precisam se organizar em torno de processos de ensino-aprendizagem que assegurem aos sujeitos envolvidos a sensibilização para o reconhecimento e uso dos gêneros textuais/discursivos que movimentam, estabilizam e emergem dessas práticas. (BALTAR, 2010, p. 179)

Desse modo, ao se trabalhar com projetos de letramento, pode-se promover uma visão crítica acerca da realidade presente no cotidiano, no contexto local, para assim questionar essa realidade mais ampla e transformá-la. 0 autor ainda destaca o papel dos gêneros textuais/discursivos para as práticas de leitura e escrita, afirmando que eles movimentam, estabilizam e emergem da prática social (BALTAR, 2010).

Oliveira (2008, p. 115) relaciona os projetos de letramento com o conceito de práticas de letramento, evidenciando a rede de componentes presente nos projetos: 
os projetos integram uma rede de componentes que evidenciam sujeitos biográficos, formas alternativas de usar o tempo e o espaço, instrumentos materiais e simbólicos e maneiras de agir individual e coletivamente. Eles buscam esclarecer e resolver situaçõesproblema e/ou questões de interesse de uma determinada comunidade, visando atingir acordos ou entendimentos compartilhados a partir da coordenação de ações coletivas e do trabalho reflexivo dos sujeitos sociais.

Oliveira (2008) explica que aprender por projetos não significa simplesmente fazer um projeto, ou seja, "textualizar um 'programa de trabalho' a ser cumprido na sala de aula de forma interdisciplinar" (2008, p. 114-5), pois os projetos não são um método de ensino ou uma receita didática. Os projetos de letramento envolvem uma "ação política e ética" (2008, p.115) que busca desenvolver a autonomia do cidadão baseando-se no desenvolvimento da consciência e também da responsabilidade social. Vale ressaltar que os projetos de letramento emergem da prática social e/ou do interesse dos estudantes, ou seja, visam resolver e esclarecer situações que, na prática social, são um problema ou questões de interesse da comunidade escolar.

Sendo assim, de acordo com Rojo (2009), o ensino deve possibilitar aos alunos a participação em várias práticas sociais que utilizam os letramentos de maneira ética, crítica e democrática. Além disso, educação linguística deve levar em consideração os multiletramentos, isto é, "a multiculturalidade característica das sociedades globalizadas e a multimodalidade dos textos por meio dos quais a multiculturalidade se comunica e informa" (ROJO; MOURA, 2012, p. 13).

Diante do exposto, nos projetos de letramento todos ensinam e aprendem de acordo com os interesses coletivos do grupo. Além disso, os conhecimentos e gêneros discursivos a serem trabalhados no projeto vêm da prática social e isso implica uma concepção transdisciplinar de conhecimento (OLIVEIRA, 2008), ou seja, não se trabalham apenas a leitura e a escrita per se, mas sim os usos da leitura e da escrita nas práticas sociais.

Nos projetos de letramento, a prática social é o componente que informa e subsidia o trabalho do professor. Diante disso, o professor pode assumir o papel de um educador crítico (RAJAGOPALAN, 2003), promovendo uma visão crítica de mundo e o questionamento de práticas excludentes e desiguais.

Ao elencar esses pontos em um projeto de letramento, acredita-se que "a escola pode formar um cidadão flexível, democrático e protagonista, que seja multicultural em sua cultura e poliglota em sua língua" (ROJO, 2009, p. 115). Isso significa que, por meio dos projetos de letramento, os alunos podem desenvolver seu pensamento crítico e reflexivo buscando a transformação social no contexto em que vivem. Na próxima seção, será tratado o papel da linguagem, dos gêneros do discurso e da leitura em projetos de letramentos. 


\subsection{A LINGUAGEM, OS GÊNEROS DO DISCURSO E A LEITURA NO ENSINO POR MEIO DE PROJETOS DE LETRAMENTO}

A nível nacional, há a Base Nacional Comum Curricular (BNCC) (BRASIL, 2017), que orienta o trabalho do professor. Esse documento destaca o texto como o aspecto central no ensino de língua portuguesa:

a centralidade do texto como unidade de trabalho e as perspectivas enunciativo-discursivas na abordagem, de forma a sempre relacionar os textos a seus contextos de produção e o desenvolvimento de habilidades ao uso significativo da linguagem em atividades de leitura, escuta e produção de textos em várias mídias e semioses. (BRASIL, 2017, p. 63).

A BNCC compartilha uma visão de linguagem na perspectiva enunciativodiscursiva que dialoga com a perspectiva bakhtiniana, em que a linguagem se materializa em enunciados que, segundo Bakhtin "possuem formas relativamente estáveis e típicas de construção do todo" (BAKHTIN, 2011, p. 282), ou seja, falamos por meio dos gêneros do discurso.

Volochínov (2017 [1929]), ao discorrer sobre a natureza sígnica e ideológica da linguagem, afirma que a palavra é a detentora de conteúdo ideológico, presente em contextos de interação verbal. Segundo o autor, "a palavra está sempre repleta de conteúdo e de significação ideológica ou cotidiana" (VOLOCHÍNOV, 2017 [1929], p. 181) e "é um ato bilateral" (p. 205). Nesse sentido, a palavra não pode ser concebida de modo abstrato; ela deve ser considerada em enunciados, que são definidos como "[...] um elo na cadeia ininterrupta de discursos verbais" (VOLOCHÍNOV, 2017 [1929], p. 184).

Nesse sentido, Bakhtin (2011) afirma que o emprego da língua ocorre em forma de enunciados concretos e únicos que são proferidos em uma esfera da atividade humana, refletindo as condições específicas e as finalidades dessa esfera por meio de seu conteúdo temático, estilo e construção composicional. Para o autor, cada enunciado é individual, mas cada campo de utilização da língua, isto é, cada esfera da atividade humana, elabora seus "tipos relativamente estáveis de enunciados" (BAKHTIN, 2011, p. 262), que são os gêneros do discurso. Sendo assim, todo uso da linguagem se dá em uma esfera da atividade humana e se materializa por meio dos enunciados, concretos, únicos e situados sócio-historicamente, isto é, os gêneros do discurso. Desse modo, é por meio dos gêneros do discurso que os usos sociais da leitura e da escrita se concretizam.

Para Santos Marques e Kleiman (2019), os projetos de letramento se vinculam à concepção bakhtiniana de linguagem e aos usos da leitura e escrita por meio dos gêneros do discurso. Além disso, como mencionado anteriormente, os projetos de letramento buscam envolver os alunos em práticas de leitura e escrita de modo crítico, visando a transformação social; por isso, também se vinculam à noção de ação social, presente na Nova Retórica (BAZERMAN, 2005, 2006). Nessa perspectiva, Bazerman (2005, p. 31) afirma que os "gêneros emergem nos processos 
sociais em que pessoas tentam compreender umas às outras suficientemente bem para coordenar atividades e compartilhar significados com vistas a seus propósitos práticos", ou seja, os gêneros estão sempre relacionados com a ação social humana, atuando como um instrumento para possibilitar a interação, o que coaduna com a concepção de agentes de letramento (KLEIMAN, 2006).

Para a BNCC (2017), o ensino de língua portuguesa deve

proporcionar aos estudantes experiências que contribuam para a ampliação dos letramentos, de forma a possibilitar a participação significativa e crítica nas diversas práticas sociais permeadas/constituídas pela oralidade, pela escrita e por outras linguagens. (BRASIL, 2017, p. 63-4).

Tal visão é compartilhada com os pressupostos teóricos dos projetos de letramento discutidos anteriormente, pois eles buscam também proporcionar o contato com textos que circulam na sociedade, a fim de promover um ensino crítico reflexivo e democrático.

Em relação à leitura, a Base Nacional Comum Curricular (BNCC) afirma que a leitura deve envolver as práticas de linguagem que "decorrem da interação ativa do leitor/ouvinte/espectador com os textos escritos, orais e multissemióticos e de sua interpretação" (BRASIL, 2017, p. 67). Sendo assim, os estudantes devem ser envolvidos em práticas de leitura dos mais diversos gêneros de modo a interpretar seu uso social, seu contexto sócio-histórico, suas intenções e valorações.

Como a linguagem se materializa em gêneros discursivos, as práticas de leitura nos projetos de letramento devem utilizá-los de acordo com a prática social do projeto. Brandão e Tinoco (2017) destacam que os gêneros nos projetos de letramento são utilizados com o intuito de "atender a determinados propósitos, visto que a escrita se insere em uma demanda legítima de uso." (BRANDÃO; TINOCO, 2017, p. 189). Desse modo, os gêneros do discurso sempre serão contextualizados e responderão à prática social.

Nos projetos de letramento, o fazer pedagógico ocorre, segundo Kleiman (2007, p. 6), partindo “[...] da prática social para o 'conteúdo' (procedimento, comportamento, conceito) a ser mobilizado para poder participar da situação, nunca o contrário [...]". Ou seja, primeiro é estabelecido, coletivamente, o problema a ser resolvido no contexto social ou a prática social que interessa aos estudantes, para então se fazer a escolha dos gêneros e conteúdos que emergem dessa prática. Os gêneros discursivos que envolverão as práticas de leitura são aqueles de interesse para a prática social dentro do projeto de letramento.

Desse modo, é a prática social que orientará as práticas de leitura nos projetos de letramento, "fazendo emergir situações-problema e atividades em que a leitura e a escrita assumem funções sociais que lhes conferem autenticidade e, ao mesmo tempo, motivação e sentido às ações dos alunos." (BRANDÃO; TINOCO, 2017, p. 185). Portanto, a escolha dos gêneros discursivos para as práticas de leitura, nos projetos de letramento, sempre emergirá do conteúdo transdisciplinar abordado no projeto que advém da prática social, ou seja, do interesse coletivo dos estudantes ou da situação-problema trabalhada no projeto. Nesse sentido, Brandão e Tinoco 
(2017) destacam que o lugar dos gêneros discursivos em projetos de letramento é o "lugar de ação social; lugar de conhecimentos partilhados; lugar de integração entre a escola e as esferas externas a ela." (2017, p. 195).

Na próxima seção, serão analisados exemplos da literatura de como ocorrem as práticas de leitura em projetos de letramento.

\section{LEITURA NOS PROJETOS DE LETRAMENTOS: REFLEXÕES METODOLÓGICAS}

Nessa seção serão analisadas algumas propostas presentes na literatura de projetos de letramento, focando nas práticas de leitura como ponto de partida para outras práticas de leitura e escrita, em relação com a prática social.

Kleiman (2012) exemplifica um projeto de letramento que busca evitar o corte de árvores do bairro para abrir espaço para uma pista de carros. A autora propõe que esse projeto seja iniciado pela seleção dos textos sobre o assunto para divulgar o projeto e envolver os estudantes em práticas de escrita situadas e relacionadas à problemática selecionada, como cartas de leitor ao jornal da cidade, cartas às autoridades locais a fim de impedir o corte das árvores, slogans e cartazes para divulgar o projeto e envolver mais pessoas. Nesse projeto, a escolha dos gêneros discursivos é de muita importância, visto que, segundo Kleiman (2012), os estudantes terão que ler textos da área de ciências, leis sobre a problemática do desmatamento, e outros textos a fim de construir argumentos convincentes para a posterior escrita das cartas de leitor e cartas às autoridades, como também para a elaboração dos slogans. Sendo assim, percebe-se que a leitura, num projeto de letramento, está interligada à prática social do projeto, a fim de possibilitar a ação social. Como mencionado pela autora, "a ênfase recai na ação e, como é fato que agimos no mundo social através de textos, escritos ou falados, a atividade linguística letrada será central." (KLEIMAN, 2012, p. 30).

Santos Marques e Kleiman (2019) relatam um projeto de letramento que objetivou a ampliação da competência leitora e escritora de alunos de duas turmas do segundo ano do Ensino Médio, no ano de 2005. Nesse projeto de letramento, o tema de interesse dos estudantes foi o desarmamento, que estava sendo muito discutido no Brasil na época, devido à realização de um referendo popular em que os cidadãos votaram se eram contra ou a favor da proibição do comércio de armas de fogo e munição no país. De acordo com Santos Marques e Kleiman (2019), a temática bastante polêmica dividiu as opiniões dos estudantes envolvidos no projeto como também da comunidade escolar, tanto em nível local como global.

As autoras destacam que temas bastante abordados na mídia, "favorece [m] o trabalho com a leitura (e com a escrita também) na sala de aula, pois a circulação de textos com a discussão da problemática se amplia de forma que até a mobilização de recursos pelo professor ocorre mais facilmente" (SANTOS MARQUES; KLEIMAN, 2019 , p. 24). Sendo assim, uma das maneiras de trabalhar a leitura de textos que circulam na sociedade é buscando na mídia assuntos que tiveram bastante destaque nas práticas sociais de determinado contexto social.

De acordo com Santos Marques e Kleiman (2019), durante a realização do projeto acerca do desarmamento, os estudantes sugeriram a organização de um 
debate regrado. Para isso, destaca-se novamente a importância da leitura, que foi o ponto de partida para essa e outras ações. As autoras afirmam que, com a produção do debate, houve alunos com diferentes posicionamentos, e que, a partir do posicionamento assumido, os estudantes fizeram a leitura de diferentes gêneros discursivos em diferentes ambientes de aprendizagem (sala de aula, biblioteca e laboratório de informática), "desterritorializando as práticas de letramento e dinamizando o processo de ensino." (2019, p. 24). Outro evento de letramento relatado no projeto foi uma pesquisa de opinião, envolvendo estudantes, professores e funcionários da escola e uma pesquisa on-line no site da escola, de modo a envolver a comunidade escolar.

Santos Marques e Kleiman (2019) destacam que o laboratório de informática da escola foi muito importante para o projeto, pois nele foram feitas oficinas de leitura para a organização de um fórum on-line. Assim os alunos tiveram acesso tanto aos jornais locais quanto aos jornais de circulação nacional. Vale ressaltar que, nessas oficinas, os alunos tiveram a oportunidade de imprimir à leitura o caráter de prática social, pois escolhiam o que leriam de acordo com o seu interesse (SANTOS MARQUES; KLEIMAN, 2019).

Uma das oficinas de leitura englobada no projeto de letramento relatado por Santos Marques e Kleiman (2019) foi sobre o gênero discursivo charge, que, segundo os autores, desempenha um papel muito importante na formação crítica. Esse gênero "favorece a construção de pontos de vista e de visões de mundo sobre a realidade econômica, social e política dos educandos." (SANTOS MARQUES; KLEIMAN, 2019, p. 26). Nessa oficina, as autoras afirmam que houve, após a prática de leitura, uma etapa de exposição dialogada das marcas e especificidades do gênero, devido a sua complexidade para os estudantes. Além disso, as autoras (2019, p. 29) destacam que essa oficina gerou muitas ideias para novas atividades no projeto, como "uma pesquisa de opinião, uma carta aberta a ser entregue em uma mobilização na rua, com faixas, a fim de formar a opinião da população". Isso demonstra o papel da leitura como ponto de partida para outras práticas de leitura e escrita, ou seja, "a leitura serve de ponte para transpor os alunos, quando se tornam leitores proficientes, a processos altamente criativos." (SANTOS MARQUES; KLEIMAN, 2019, p. 30).

Com base nas propostas acima apresentadas, destaca-se a relevância de os projetos de letramento estarem implicados com o contexto local e global no qual os estudantes estão inseridos. Sendo assim, não se trata de ler apenas para praticar a leitura, de modo tecnicista e descontextualizado da realidade. As propostas acima apresentadas indicam a pertinência de os projetos de letramento abrangerem diferentes fontes de informação de modo a complexificarem as análises sobre os temas discutidos. Acredita-se que, dessa forma, é possível instrumentalizar os estudantes para a produção de análises atentas aos diversos discursos que atravessam e constituem os textos, e os contextos sociais e políticos nos quais esses foram produzidos.

Vale destacar, a partir da perspectiva da pedagogia crítica defendida por Saviani (2005), a relevância de os projetos de letramento subverterem as práticas que os reduzem à leitura de textos tidos como de "prestígio social", buscando incorporar os mais variados gêneros discursivos presentes em diferentes contextos sociais, locais e globais. Assim, é possível desafiar a escola a construir práticas 
comprometidas com o desenvolvimento do pensamento crítico sobre a realidade social.

\section{CONSIDERAÇÕES FINAIS}

Este artigo teve como objetivo discutir os conceitos pertencentes à perspectiva dos Novos Estudos do Letramento, teorizar sobre as práticas de leitura em projetos de letramento e também analisar duas propostas presentes na literatura que corroboram essa perspectiva.

Partindo da concepção enunciativo-discursiva de linguagem, a leitura de textos promove o pensamento crítico, reflexivo e responsivo, à medida que possibilita o diálogo do estudante com o texto, seu autor e outras vozes. Isso porque, a partir do diálogo com um texto/enunciado, o leitor manifesta uma atitude responsiva ativa: concordando, discordando, completando, etc. Sendo assim, a leitura é ativa e responsiva (BAKHTIN, 2011).

Conclui-se que é a prática social que definirá os gêneros discursivos que serão abordados nas práticas de leitura e de escrita nos projetos de letramento. Portanto, é a partir de interesse coletivo dos estudantes ou de algum problema social que o projeto de letramento toma forma e possibilita a seleção dos gêneros discursivos a serem utilizados. Cabe ressaltar a importância da leitura nos projetos de letramentos, pois ela pode ser o ponto de partida para práticas de letramento mais críticas e criativas.

\section{Referências}

BAKHTIN, M. M. Estética da criação verbal. Introdução e tradução do russo Paulo Bezerra. 6. ed. São Paulo: WMF Martins Fontes, 2011.

BALTAR, M. Letramentos e gêneros textuais midiático-escolares. Letras, Santa Maria, v.20, n. 40, p. p. 177-190, jan./jun. 2010. Disponível em https://periodicos.ufsm.br/letras/article/view/12151/7545. Acesso em 24 mar. 2020.

BARTON, David; HAMILTON, Mary. Understanding literacy as social practice. Local Literacies: reading and writing in one community. London: Routledge, 1998. BAZERMAN, C. Gêneros textuais, tipificação e interação. São Paulo: Cortez, 2005.

BAZERMAN, C. Gênero, agência e escrita. São Paulo: Cortez, 2006.

BRANDÃO, L. C. L.; TINOCO, G. M. A. M. O lugar dos gêneros discursivos em projetos de letramento. Caminhos em Linguística Aplicada, v. 1, p. 178-198, 2017. Disponível

em: 
http://periodicos.unitau.br/ojs/index.php/caminhoslinguistica/article/view/231 7/1664. Acesso em 23 mar. 2020

BRASIL. Base Nacional Comum Curricular. Brasília: MEC, 2017. Disponível em: http://portal.mec.gov.br/index.php?option=com docman\&view=download\&alias= 79601-anexo-texto-bncc-reexportado-pdf-2\&category slug=dezembro-2017pdf\&Itemid=30192. Acesso em 19 mar. 2020.

FREIRE, P. Pedagogia da autonomia: saberes necessários à prática educativa. São Paulo: Paz e Terra, 1996.

FREIRE, P. A importância do ato de ler: em três artigos que se completam. 45.ed São Paulo: Cortez, 2003.

GEE, J. P. Background to the 'New Literacy Studies'. In: GEE, J. P. Social Linguistics and Literacies: Ideology in Discourses. Londres: Taylor \& Francis, 1994. p. 49-70.

GIROUX, Henry. Introdução. In: FREIRE, P.; MACEDO, D. Alfabetização: leitura do mundo, leitura da palavra. Rio de Janeiro: Paz e Terra, 1990. p. 01-27.

HAMILTON, M. Expanding the new literacy studies: using photographs to explore literacy as social practice. In: BARTON, David; HAMILTON, Mary; IVANIC, Roz (Org.) Situated literacies. London: Routledge, 2000. p. 16. 35.

HEATH, S. B. What no bedtime story means: Narrative skills at home and school. Language in Society. v 11, p. 49-76, 1982.

KALMAN, J. El acesso a la cultura escrita: la participación social y la apropiación de conocimientos en eventos cotidianos de lectura y escritura. Revista Mexicana de Investigación Educativa, Consejo Mexicano de Investigación Educativa. México, v. VIII, n. 17, p. 37-66, enero/abr. 2003.

KLEIMAN, A. B. Modelos de letramento e as práticas de alfabetização na escola. In: KLEIMAN, Angela B. (Org.). Os significados do letramento: uma nova perspectiva sobre a prática social da escrita. Campinas, SP: Mercado de Letras, 1995, p. 15-61.

KLEIMAN, A. B. O processo de aculturação pela escrita: ensino da forma ou aprendizagem da função?. In: KLEIMAN, A.; Signorini, I. (Orgs.). 0 ensino e a formação do professor: alfabetização de jovens e adultos. Porto Alegre: Artes Médicas, 2000. p. 223-243.

KLEIMAN, A. B. Processos identitários na formação profissional - o professor como agente de letramento. In: CORRÊA, M. L. G.; BOCH, F. (Orgs.). Ensino de língua: representação e letramento. Campinas: Mercado de Letras, 2006. p. 75-91.

KLEIMAN, A. B. Letramento e suas implicações para o ensino de língua materna. Signo, Santa Cruz do Sul, v. 32 n 53, p. 1-25, dez. 2007. Disponível em: 
https://online.unisc.br/seer/index.php/signo/article/view/242/196. Acesso em 23 mar. 2020.

KLEIMAN, A. B. Projetos de Letramento na Educação Infantil. Revista Caminhos em Linguística Aplicada, UNITAU. v. 1, n. 1, p. 1-10, 2009. Disponível em: http://periodicos.unitau.br/ojs/index.php/caminhoslinguistica/article/view/898 1716. Acesso em 23 mar. 2020.

KLEIMAN, A. B. EJA e o ensino da língua materna: relevância dos projetos de letramento. EJA EM DEBATE, Florianópolis, vol. 1, n. 1. nov. 2012. p. 23-38. Disponível

em: https://periodicos.ifsc.edu.br/index.php/EJA/article/view/874/pdf. Acesso 23 mar. 2020.

OLIVEIRA, M. do S. Projetos: uma prática de letramento no cotidiano do professor de língua materna. In: OLIVEIRA, Maria do Socorro; KLEIMAN, Ângela. (Orgs.) Letramentos múltiplos: agentes, práticas, representações. Natal: EDUFRN, 2008. p. 93-118.

OLIVEIRA, Maria do Socorro. Gêneros textuais e letramento. Rev. bras. linguist. apl., Belo Horizonte , v. 10, n. 2, p. 325-345, 2010. Disponível em: http://www.scielo.br/scielo.php?script=sci arttext\&pid=S198463982010000200003\&lng=en\&nrm=iso. Acesso em 23 mar. 2020.

OliVEIRA, M do S.; TINOCO, G. A.; SANTOS, I. B. A. Projetos de Letramento e formAÇÃo de professores de língua materna. Natal: EDUFRN, 2014. 116 p. Disponível em: https://repositorio.ufrn.br/jspui/bitstream/1/11787/1/Ebook\%20Projetos\%20de\%20letramento.pdf. Acesso em 23 mar. 2020.

PENNYCOOK, A. A linguística aplicada dos anos 90: em defesa de uma abordagem crítica. In: SIGNORINI, I; CAVALCANTI, M. (Orgs.). Linguística aplicada e transdisciplinaridade: questões e perspectivas. CAMPINAS, SP: Mercado de Letras, 1998. p. 21-46.

RAJAGOPALAN, K. Por uma linguística crítica: linguagem, identidade e a questão ética. São Paulo: Parábola, 2003.

ROJO, R. Letramentos múltiplos: escola e inclusão social. São Paulo: Parábola Editoria, 2009.

ROJO. R; MOURA, E. Multiletramentos na escola. São Paulo: Parábola, 2012.

SANTOS MARQUES, I. B. A. S.; KLEIMAN, A. B. Projetos, oficinas e práticas de letramento: leitura e ação social. Revista ComSertões, [S.l.], v. 7, n. 1, p. 16-34, nov. 2019.

em: http://www.revistas.uneb.br/index.php/comsertoes/article/view/7275. Acesso em 17 mar. 2020. 
SAVIANI, D. Pedagogia histórico-crítica: primeiras aproximações. 9.ed. Campinas: Autores Associados, 2005.

STREET, B. V. Literacy in theory and practice. Cambridge: Cambridge University Press, 1984.

STREET, B. V. Abordagens alternativas ao letramento e desenvolvimento. Teleconferência Unesco Brasil sobre 'Letramento e Diversidade', outubro de 2003.

STREET, B. V. Literacy events and literacy practices: theory and practice in the New Literacy Studies. In: JONES, Marilyn Martin; JONES, Kathryn. Multilingual Literacies: reading and writing different worlds. Amsterdam: John Benjamins, 2000 .

VENCATO, A. P. Diferenças na escola. In R. Miskolci e J. Leite Júnior (Orgs.), Diferenças na educação: Outros aprendizados. São Carlos, SP: EdUFSCar. 2014, p. 19-56.

VOLOCHÍNOV, V. N. Marxismo e filosofia da linguagem: problemas fundamentais do método sociológico na ciência da linguagem. Tradução, notas e glossário de Sheila Grillo e Ekaterina Vólkova Américo. 1 ed. São Paulo: Editora 34, 2017 [1929].

\section{Para citar este artigo}

GESSER, A. R. Práticas de leitura em projetos de letramento: reflexões teórico-metodológicas. Macabéa Revista Eletrônica do Netlli, Crato, v. 10, n. 1, 2021, p. 67-82.

\section{A autora}

ANDRESSA REGIANE GESSER é doutoranda em Linguística pela UFSC, pelo Programa de Pós-Graduação em Linguística, na área de Linguística Aplicada, mestra em Linguística pela UFSC, pelo Programa de Pós-Graduação em Linguística, na área de Linguística Aplicada e graduada em Letras- Português/ Inglês e respectivas literaturas pela FURB - Universidade Regional de Blumenau. 